\title{
ENDODONTICS PROCEDURAL ERRORS; DETECTING IN CONVENTIONAL VERSUS ROTARY ROOT CANAL THERAPY drsunilpanjabi@yahoo.com
}

1. BDS, MSc

Lecturer

Department of Operative Dentistry

Faculty of Dentistry,

LUMHS, Jamshoro

2. BDS, MSc, MBE

Lecturer

Faculty of Dentistry,

LUMHS, Jamshoro

3. BDS, MSc

Clinical AMS

Dental Department

Liaquat University Hospital,

Hyderabad

4. BDS, FCPS

Assistant Professor Oral \&

Maxillofacial Surgery

Faculty of Dentistry,

LUMHS, Jamshoro

Correspondence Address:

Dr Suneel Kumar Punjabi

Flat No: $3073^{\text {rdfloor Citizen Plaza }}$

Opp Aga Khan Hospital

Main Jamshoro Road,

Qasimabad, Hyderabad

drsunilpanjabi@yahoo.com

Article received on:

08/08/2016

Accepted for publication:

20/10/2016

Received after proof reading:

00/00/2016

\section{Dr. Naveen Khawaja1, Dr. Ramesh Lal ${ }^{2}$, Dr. Mujeeb Rehman ${ }^{3}$, Dr. Suneel Kumar Punjabi ${ }^{4}$}

\begin{abstract}
The rationale of this study was to assess the results of training endodontic to postgraduates. This study was assumed to evaluate the procedural quality of root canal obturation and occurrence of ritual errors in the root canal treatment cases performed by postgraduates in the department of Operative Dentistry. Study Design: Cross sectional case series study. Setting: Department Operative Dentistry, Liaquat University of Medical Health Science, Jamshoro. Period: May 2014 to Apr 2016. Methodology: Total two hundreds eighty eight cases were evaluated, out of which 144 were prepared using Pro-taper universal (Dentsply) rotary system and 144 were prepared using conventional hand file system. Each group of teeth was evaluated by radiograph for the occurrence or lacking of procedural errors i-e overfill, under fill, instrument separation. Results: Among 288 cases, out of 144 conventionally treated teeth $58(49 \%)$ had procedural errors. Whereas out of 144 teeth treated with Pro-taper next rotary system, $61(51 \%)$ had technical errors. Most of errors seen in both groups but farthest were overfill. Chi square test showed $\mathrm{P}$ value $>0.05(0.416)$ which illustrate an irrelevant relationship among the systems applied \& the incidence of errors. Conclusion: There was variation among overfill \& under fill prevalence of practical errors in both systems; nonetheless, there was a disparity in the nature of error produced. It is accomplished that even though rotary systems are not as simple to use as formerly alleged.
\end{abstract}

Key words: $\quad$ Procedural errors, Conventional, Root canal therapy, Rotary

Article Citation: Khawaja N, Lal R, Rehman M, Punjabi SK. Endodontics procedural errors; detecting in conventional versus rotary root canal therapy. Professional Med J 2016;23(12):1537-1540. DOI: 10.17957/TPMJ/16.3566

\section{INTRODUCTION}

Successful endodontic therapy depends on many factors, one of the imperative steps in the endodontic treatment is canal preparation, to clean \& shape the root canal system efficiently while maintaining its configuration exclusive of creating any mishaps or procedural errors. Unfortunately procedural accidents happen during endodontic treatment, such as instrument separation; overfill, under fill, ledge formation; or perforation and external transportation. ${ }^{1}$

Main problems occur during preparation of curved canals. As stainless steel files are used, there is increased tendency for each preparation techniques to make the prepared canal far from its original axis. Divergence from the innovative curvature can direct to practical errors, like, zipping, stripping or perforations, ledge formation. ${ }^{2}$
While procedural errors are occur in every approaches of root canal treatment. The main concern in endodontics now a day is to reduce the numbers of such errors from occurring, whilst maintaining the quality and efficiency of recent therapy modalities. Conventional endodontic therapy has been overwhelmed with a high risk of many errors. ${ }^{3}$

Introduction of nickel-titanium files has made endodontics a conventional root canal treatment $\&$ is more knowable and well-organized. But, despite upgrading in the metal alloys \& file designs, still separation of rotary instruments during endodontic treatment is a challenging, surplus \& wearisome complication. Mostly fracture of endodontic file results from erroneous use or overuse. ${ }^{4}$ 
On the other hand rotary files are not susceptible to such problems either but the occurrence of such errors has markedly reduced since familiarized new rotary devices. ${ }^{3,5}$

Regrettably dental practitioners despite the immense advantages offered by rotary endodontics select to use conventional hand files.

The aim of present survey was to study the incidence of technical errors occuring during performing root canal treatment with conventional \& rotary.

\section{METHODOLOGY}

This cross sectional case series study was performed at Department: Operative Dentistry, Liaquat University of Medical \& Health Sciences, Jamshoro. A sample size of 288 was chosen, all permanent teeth of both jaws maxillary and mandibular teeth (except for the third molars) were treated using both conventional stainless steel files and rotary systems (Pro-taper universal [Dentsply]) by postgraduate trainees from May, 2014 to April, 2016. Patients more than 65 years and below 12 years were excluded from this study, as these teeth possessing open apices or blocked or calcified canals.

\section{Data Collection}

All endodontical treated teeth that fulfilled the inclusion criteria were included in this study, the digital periapical radiographs (taken with a paralleling technique and stored using Ondye France $\left.{ }^{\circledR}\right)$ of these teeth were grouped into categories:

1. Treatment with conventional files

2. Treatment with rotary files

Teeth treated with conventional files were equipped using the crown down technique with stainless steel hand files and obturated with lateral condensation technique. Coronal flaring was initially done using Gates-Glidden burs. K-files were used to shape the canals in the following sequence; \#50, \#45, \#40, \#35, $\# 30$. Size 30 was taken as the Master apical file
(MAF). Working length was considered suitable if it was within $0-2 \mathrm{~mm}$ of the radiographic apex as determined by a periapical radiograph.

Teeth treated with rotary system were prepared using Pro-taper universal system (Dentsply). After establishing working length with a periapical radiograph (using a paralleling technique), cleaning and shaping was done using the filing sequence as mentioned by the manufacturers (i.e. SX, S1, S2, F1, F2 for posterior teeth and till F3 for anterior teeth). In both filing techniques (conventional and rotary) a patency file was used in between each successive file used and the canal was copiously irrigated with the solution of sodium hypochlorite $5 \%$.

Teeth in every group were assessed for presence or absence of technical errors (i.e. overfill, under fill, instrument separation \&/or apical transportation). Based on the presence or absence of procedural errors, radiographs were divided into two categories:

1. Acceptable RCT

2. Faulty RCT.

Teeth without procedural error were included in the "Acceptable RCT" category. Those with a procedural error were included in the "Faulty RCT" category. Occurrence for individual error and percentages of acceptable and faulty RCT were calculated for both groups. The percentage of faulty treatment and types of errors in both groups were compared. Radiographs were assessed by two senior clinicians and professor of the department.

Data was analyzed using SPSS version 21. Chi square test was used to test the $P$ value \& presented in figures.

\section{RESULTS}

The 288 root canal treated teeth were evaluated, out of them 144 were conventional root canal treatments and 144 were done using the rotary filing system. Out of 288 male patients were (35\%) and $(65 \%)$ were female patients. As shown in Figure-1. Out of 288 patients (29.16\%) belonged 
to 31 to 40 years of age. As shown in Figure-2. Out of the 144 conventionally treated teeth 58 (49\%) were found to have a practical error. Out of 144 cases done with rotary system, 61 (51\%) were found to contain procedural errors. As shown in figure-3. Usually errors in either groups were overfilling. As shown in figure-4. Chi square test signify $P$ value $>0.05(0.416)$ which illustrate an immaterial relationship among the system used and the occurrence of errors.

\section{Gender}

Male Female

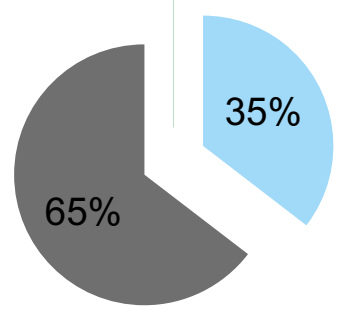

Figure-1. Gender Distribution

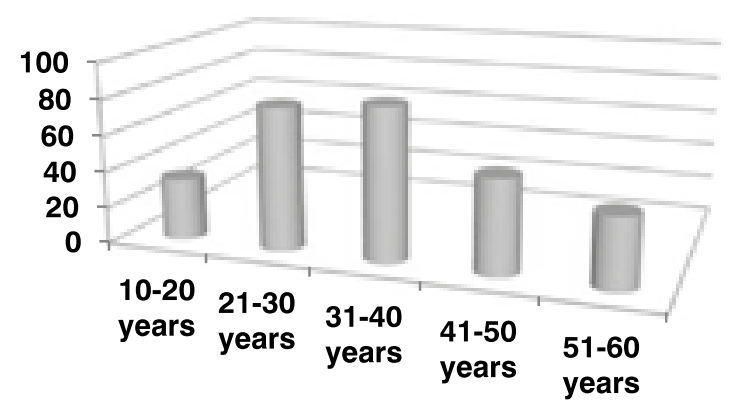

Figure-2. Age Distribution in year

Procedural Errors

Conventional RCT $\quad$ Rotary RCT

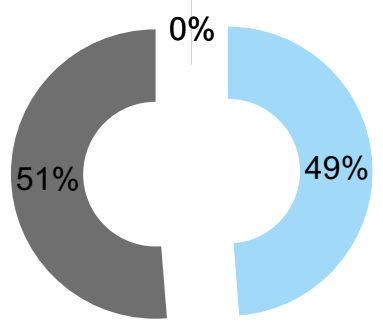

Figure-3. Procedural Errors Conventional versus Rotary filing system

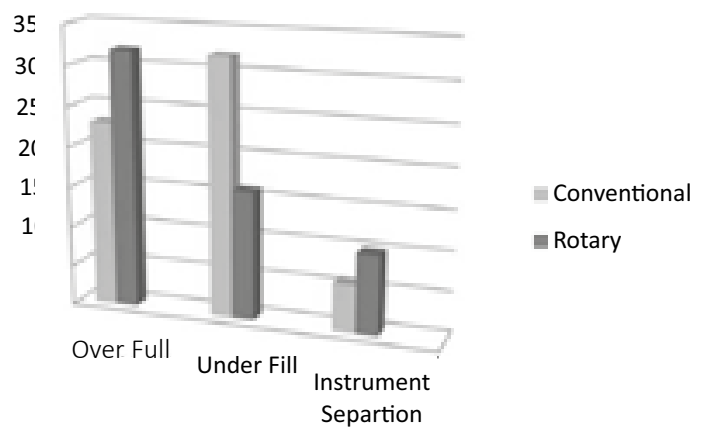

Figure-4. Frequency of errors in Root Canal Treatment done using Conventional and rotary filling system

\section{DISCUSSION}

Endodontic training required scientific information and proper methodological approach to optimize the use of resources and techniques. numerous disputes are faced throughout postgraduate training; the present study illustrated that conventional root canal treatment is as effective as rotary based systems in avoiding procedural errors. This study revealed procedural errors can happen irrespective of the filing system used. While there seemed to be slightly less procedural errors when the conventional root canal treatment was employed, this was not a statistically significant finding. During the course of this present study procedural errors were noted, overfill was the most common error in both groups $(15.97 \%$ in conventional and $22.22 \%$ in rotary). While, this may not be directly related with canal preparation by both systems. In fact, mostly related to improper working length determination, obturation or overinstrumentation and an inability to provide proper taper. ${ }^{6}$ Thus, it is skill of the operator that performs the role in proper working length determine and not the filing system being used. Rotary system was noted to have a considerably more frequent appearance of overfills in the present sample. This may be more expertise required in its application. Underfill occurred more in conventional cases with frequencies i-e $22.22 \%$ and less frequently occurred in rotary system $11.11 \%$. It was also noted that incidence of instrument separation was greater in rotary systems.as compared to Conventional file system in the sample. This finding indicated that rotary systems are more prone to this type of procedural error. This can be attributed to cyclic Fatigue 6 experienced by 
rotary instruments which is a problem not readily apparent upon repeated use of NiTi systems. On the other hand stainless steel files are more resilient to fracture and provide easily identifiable clues (e.g. visible unwinding of flutes, tip distortion, roll-up of flutes, corrosion) ${ }^{7}$ prior to separation. We cannot recommend the use of rotary file systems over their conventional counterparts on the basis of procedural errors produced, but it is undeniable that rotary systems are faster, more convenient and comfortable for the patient as well as the clinician. It is rare for conventional root canal treatment to be completed in less than 3 visits, whereas, if the conditions are favorable, rotary root canal treatment can be completed within a single appointment. Therefore our recommendation is that dentists should develop the necessary skills to handle these systems more effectively to minimize the procedural errors.

\section{CONCLUSION}

Doctors should provide better care to sustain accurateness of the working length right through the procedure, as by far errors in length are responsible for the majority of errors. Nevertheless, there was a variation in the nature of error occurred. Rotary endodontics tended to produce significantly greater incidence of overfill and instrument separation whereas conventional showed a somewhat greater occurrence of under fill. It is accomplished that even though rotary systems are not as simple to use as formerly alleged.

Copyright@ 20 Oct, 2016.

\section{REFERENCES}

1. Guelzow A, Stamm O, Martus P, Kielbassa AM. Comparative study of six rotary nickel-titanium systems and hand instrumentation for root canal preparation. IntEndodon J.2005; 38: 743-752.

2. Gambarini G. Rationale for the use of low torque endodontic motors in root canal instrumentation. Endod Dent Traumatol. 2000; 16: 95-100.

3. YousufW, khan M, Sheikh A. Frequency of procedural errors in rotary vs conventional root canal treated teeth. Pakistan Oral \& Dent J.2015;35(3): 524-526

4. Jiménez-Ortiz JL et al. Rotary instrumentation: usage, separation and effect on postoperative endodontic complications. Revista Odontológica Mexicana 2014;18 (1): 27-31

5. Chen JL, Messer HH. A Comparison of Stainless Steel Hand and Rotary Nickel-Titanium Instrumentation Using a Silicone Impression Technique. Aust Dent $\mathrm{J}$. 2002; 47(1): 12-20.

6. Walton RE, Torabinejad M. Principles and practice of endodontics. 3rd ed. Philadelphia: W.B. Saunders Company; 2002. Pg 159

7. Haji-Hassani N, Bakhshi M, Shahabi S. Frequency of latrogenic Errors through Root Canal Treatment Procedure in 1335 Charts of Dental Patients. J Inter Oral Health. 2015; 7(4): 1-4.

\begin{tabular}{|c|l|l|}
\hline \multicolumn{3}{|c|}{ AUTHORSHIP AND CONTRIBUTION DECLARATION } \\
\hline Sr. \# & \multicolumn{1}{|c|}{ Author-s Full Name } & \multicolumn{1}{c|}{ Contribution to the paper } \\
\hline 1 & Dr. Naveen Khawaja & Data collection \& Results \\
2 & Dr. Ramesh Lal & Intro, Study Design \\
3 & Dr. Mujeeb Rehman & Discussion, References \\
4 & Dr. Suneel Kumar Punjabi & Abstract \& Proof Reading \\
\hline
\end{tabular}

